\title{
EL MITO DE LOS GRANDES «HOMBRES EXPORTADORES» COMO ESTRATEGIA DE DOMINACIÓN DE LAS ÉLITES LOCALES EN UN TERRITORIO RURAL
}

The myth of the great "exporters" as a strategy of domination by local elites in a rural area

\section{Antonio José Ramírez Melgarejo \\ Universidad de Murcia. Departamento de Sociología ajrm1@um.es https://orcid.org/0000-0001-8062-0880}

RESUMEN: La Vega Alta del río Segura en la Región de Murcia es una comarca rural que, durante el último siglo, se ha ido conformando en un importante enclave productivo agrícola. Actualmente está plenamente inserto en las grandes cadenas globales de comercialización de productos en fresco para toda Europa, especializado en uva apirena y frutas de hueso. Durante su particular proceso socio-histórico, las relaciones sociales que se producen entre las diferentes clases sociales que conviven en el territorio se han ido construyendo, modificando y adaptando a los grandes cambios también sociales, sin que cambien en lo sustancial. Las élites locales constituidas como coaliciones locales de crecimiento han detentado (y detentan) poder suficiente para tratar de controlar el devenir del modelo socio-productivo local. El objetivo ha sido (y es) conservar y tratar de fortalecer su posición de poder. Para ello han sido capaces de desplegar a lo largo del tiempo estrategias de dominación adaptadas a los grandes cambios sociales y estructurales. Como ejemplo analítico presentaré tres casos prototípicos de exportadores, pertenecientes a tres generaciones diferentes, que desplegaron formas de dominación similares pero adaptadas a su tiempo.

Palabras ClaVe: coalición de crecimiento, redes clientelares, paternalism, trabajo agroindustrial, dominación. 
ABSTRACT: The Vega Alta of the Segura river in the Region of Murcia is a rural region that was forged as an important area of agricultural production during the last century. Today it is a major player in the big global chains marketing fresh produce for all Europe, specializing in seedless grapes and stone fruits. During its socio-historical development, social relations between the different social classes in the territory have been built and modified, and have adapted to major social shifts without substantial changes. The power held by local elites, established as coalitions for local growth, is still sufficient for them to attempt to control the evolution of the local socio-productive model, with the aim of preserving and strengthening their position of power. To this end, over time they have been able to deploy strategies of domination adapted to the major social and structural changes. As an analytical example I will present three prototypical cases of exporters, belonging to three different generations, who deployed similar forms of domination, each adapted to their time.

KEYWORDs: growth coalition; clientelist networks; paternalism; agroindustrial work; domination

RESUM: La Vega Alta del riu Segura a la Regió de Múrcia és una comarca rural que, durant l'últim segle, s'ha anat conformant en un important enclavament productiu agrícola. Actualment està plenament inserit en les grans cadenes globals de comercialització de productes en fresc per a tota Europa, especialitzat en raïm de variant apirena i fruites d'os. Durant el seu particular procés socio-històric, les relacions socials que es produeixen entre les diferents classes socials que conviuen en el territori s'han anat construint, modificant i adaptant als grans canvis també socials, sense que canvien en allò substancial. Les elits locals constituïdes com a coalicions locals de creixement han posseït (i posseeixen) poder suficient per a tractar de controlar l'esdevenir del model socio-productiu local. L'objectiu ha sigut (i és) conservar i tractar d'enfortir la seua posició de poder. Per a això han sigut capaços de desplegar al llarg del temps estratègies de dominació adaptades als grans canvis socials i estructurals. Com a exemple analític presentaré tres casos prototípics d'exportadors, pertanyents a tres generacions diferents, que van desplegar formes de dominació similars però adaptades al seu temps.

Paraules clau: coalició de creixement, xarxes clientelistes, paternalisme, treball agroindustrial, dominació. 


\section{Introducción}

E

n la actualidad, el modelo productivo de la comarca de la Vega Alta en la

Región de Murcia gira en torno a un sector agroindustrial avanzado, con un alto grado de tecnificación. Está posicionado como un importante enclave productivo agrícola inserto en las cadenas globales de mercancías de producción y distribución de frutas en fresco. Este enclave productivo está conformado por los municipios de Abarán, Blanca y Cieza, entre los tres suman una población de unas 54500 personas aproximadamente. El municipio más grande es el de Cieza con casi 35000, según los datos de empadronamiento de 2019. Entre los tres acumulan una superficie de $567,36 \mathrm{~km}^{2}$, por lo que la densidad poblacional es de unas 96 personas por $\mathrm{km}^{2}$, similar a la media española. Según los datos del padrón y el censo, la población en la comarca se ha mantenido estable durante las dos últimas décadas, también el porcentaje de personas de origen extranjero que se sitúa en torno al 8-9\% en Abarán y Cieza y el $12 \%$ en Blanca. Estos datos pueden considerarse bajos si se contrastan con otros enclaves productivos agrícolas regionales como Torre Pacheco, donde la población migrante alcanza picos del 30\%. Este dato, que no recoge las migraciones pendulares del trabajo ni la fuerza de trabajo no regularizada, indica que un volumen importante de mano de obra empleada en la agricultura es nativa. Es decir, miles de personas nacidas en la Vega Alta siguen empleadas en el mismo sector eventual en que trabajaron sus antepasados.

El modelo productivo agroindustrial de la Vega Alta se ha transformado notablemente en las últimas décadas. Se ha incrementado la inversión en tecnología; existe tendencia a la concentración de la propiedad de la tierra (De Castro et al., 2017) y ha aumentado el peso de grandes empresas productoras y comercializadoras cuya actividad está orientada a la exportación internacional (Arcas et al., 2014) entre otras transformaciones socio-productivas. ${ }^{1}$

1. Las transformaciones del sector agroalimentario murciano han sido ampliamente analizadas por diferentes científicos/as sociales, entre las que destacan las realizadas por los miembros del grupo de investigación EnClaves de la Universidad de Murcia. Por destacar solo algunas, véase Pedreño (1998; 1999; 2014), de Castro (2014); de Castro; Gadea y Pedreño (2014); Gadea; Ramírez y Sánchez. (2014); Gadea et al. (2015) o Ramírez (2019) 
A pesar de las importantísimas transformaciones, todavía se mantienen ciertas regularidades. Una de las que más me interesa destacar, en relación a la organización del trabajo, es que sigue siendo necesario el reclutamiento intensivo de fuerza de trabajo en las temporadas altas de producción agrícola. Es decir, el empresariado agroindustrial sigue necesitando disponer de un ejército de reserva disponible y suficiente. En este sentido, las élites locales económicas y políticas han ido conformando coaliciones de crecimiento ${ }^{2}$ (De Castro et al., 2017; Logan y Molotch, 1987), capaces de desplegar estrategias de control político y económico, con el objetivo de fijar la fuerza de trabajo en el territorio y mantener su posición de poder durante, al menos, el último siglo.

En este artículo abordaré, en primer lugar, una breve descripción analítica del devenir histórico del territorio. Posteriormente utilizaré tres ejemplos de tres «grandes hombres exportadores» pertenecientes a tres generaciones diferentes, para tratar de argumentar cómo la construcción de un mito ha contribuido a desplegar formas de dominación tradicional y carismática en el territorio. Una estrategia subjetiva de control que las coaliciones de crecimiento, compuestas por la élite económica y política local, promocionan para tratar de mantener y expandir su posición de poder en la Vega Alta.

Este artículo es resultado de mi investigación de tesis doctoral, en la que prioricé la entrada territorial y la metodología cualitativa. El paradigma

2. En un artículo coescrito con los compañeros del equipo de investigación ENCLAVES, Carlos de Castro y Andrés Pedreño, junto a la compañera Elena Gadea, definimos así esta particular coalición de crecimiento local: «Logan y Motoch (1987), en el ámbito de los estudios urbanos, señalan que es el deseo y la expectativa de crecimiento lo que crea consenso entre la coalición de los actores que impulsan los proyectos de transformación urbana (coalición de crecimiento), más concretamente, consenso entre las élites. Por su parte, Levy (2008), quien se inspira en las aportaciones de Gramsci, señala que la construcción del consenso debe incorporar elementos económicos pero también elementos políticos y culturales. La construcción de un consenso requiere por tanto el establecimiento de una afinidad económica, política y cultural entre, por un lado, los actores impulsores de la reestructuración regional para acoplarse a las RGP y, por otro lado, entre los actores impulsores y resto de la población, lo que requiere conseguir la complicidad y el respaldo generalizado de la población, lo que hace necesario conectar con sus intereses económicos y con su sensibilidad política y cultural. Además, no hay que perder de vista que esta operación de construcción de un consenso amplio se realiza siempre en una situación de desigual correlación de fuerzas entre los actores» (De Castro et al., 5: 2017) 
metodológico hipotético-deductivo fue la base sobre la que construí el diseño metodológico que complementé con el modelo metodológico configuracional (De la Garza, 2018). Las dos principales técnicas de investigación empleadas fueron la realización de entrevistas guionizadas y numerosas inmersiones etnográficas. ${ }^{3}$ De esta manera, buscaba introducirme en los intersticios de las distintas esferas económicas, laborales, sociales y morales que conforman la vida cotidiana de las clases populares trabajadoras ${ }^{4}$ de la Vega Alta del Río Segura. Mi objetivo central de investigación fue comprender la crisis económica de 2008 como una crisis de reconocimiento que producía heridas morales a la clase trabajadora, para lo que tuve que abordar tangencialmente cómo ejercían el poder las élites locales.

\section{El devenir histórico de la Vega Alta: agrarismo tradicionalista y clientelismo}

Los poderes políticos junto a propietarios y caciques comenzaron a desarrollar, desde principios del siglo xx en Murcia, una estrategia combinada de modernización e impulso de la agricultura, apostando por la generalización del arrendamiento para fortalecer la dependencia de la clase trabajadora a las estructuras de la incipiente economía capitalista patria. Los propietarios actuaron y se organizaron para defender sus intereses de clase construyendo una sólida red clientelar con el objetivo de estrechar lazos de dependencia, incrementar la productividad y rentabilidad de sus tierras y dominar la resistencia jornalera creando un relato laudatorio de la familia huertana feliz en la sumisión (Pedreño, 2014).

Lo que ocurría en Murcia y España no era más que la versión nacional de lo que estaba ocurriendo en toda Europa. Entrado el siglo xx los apar-

3. En total realicé cuarenta y dos entrevistas a personas seleccionadas según cinco perfiles definidos previamente. Para más información sobre la metodología empleada y cómo realicé el trabajo de campo, véase el capítulo tres de Ramírez (2019).

4. Entiendo «clases populares trabajadoras» en el mismo sentido que Alfonso Ortí, cuando las describió como «mujeres y hombres en situación de empleo eventual y, por tanto, en perspectiva de un probable desempleo a corto plazo» (Colectivo IOE y Ortí, 2007: 33). 
ceros, arrieros, labradores y pequeños propietarios del viejo continente vieron peligrar sus exiguas posesiones e inciertas posiciones sociales por las reivindicaciones de socialistas, comunistas y anarquistas que ya se estaban organizando y politizando en torno a partidos y sindicatos obreros que cuestionaban la propiedad privada (Ortega y Cobo, 2011).

En estas circunstancias de creciente politización y tensión social nació, en términos polanyianos, un contramovimiento de resistencia reaccionario. Estaba compuesto por todo un crisol de propietarios agrarios de toda índole que fueron posicionándose política e ideológicamente del lado de la burguesía conservadora; propietarios terratenientes y sindicalismo de raíz católica. Una amalgama que compartía el interés por proteger sus intereses como propietarios, lo que años después les llevaría a involucrase a favor de los regímenes fascistas que preconizaban defender a los pequeños propietarios a la vez que el agro y lo rural se ensalzaba como los verdaderos valores de la patria (Ortega y Cobo, 2011). La politización se acentuó con el llamado trienio bolchevique de 1918 a 1920 (Nicolás, 1999, 2003; Ortega y Cobo, 2011) es el momento en que se provocó «la definitiva segmentación interna de la mayor parte del campesinado» (Ortega y Cobo, 2011: Xv).

La dictadura de Miguel Primo de Rivera (de 1923 a 1930) fue, entre otras cosas, un intento de redirigir y apaciguar las demandas sociales del agro. El Capitán General Rivera buscó durante su mandato la colaboración de los sindicatos católicos agrarios; mantuvo los grandes latifundios (especialmente en Andalucía) pero al mismo tiempo reconoció y vigorizó al campesinado parcelario y a los pequeños propietarios agrarios como base social conservadora, para hacer frente a las reivindicaciones agrarias comunalistas de partidos y sindicatos de corte socialista y anarquista. En 1927 proclamó la ley de parcelaciones poniéndose en marcha la colonización de tierras, con el objetivo final de reconvertir a los nuevos colonos en pequeños propietarios agrícolas (Sanz, 2011). De esta manera, parte del campesinado pasó a reconvertirse en pequeños propietarios que engrosaron las filas conservadoras reaccionarias para tratar de defender su recién adquirido estatus social de propietarios (Malefakis, 1977; Castillo, 1979).

Un año después de la caída de la dictadura riverista se constituiría la II República en España. En un clima de alta inestabilidad social y política se 
sucedieron gobiernos de izquierda y derecha, hasta que en julio de 1936 un golpe de estado reaccionario, de carácter fascista, contra el gobierno izquierdista del Frente Popular propició la sangrienta Guerra Civil española. En abril de 1939 terminó la sangrienta contienda con la toma de poder del autoproclamado caudillo Francisco Franco. El mal llamado franquismo fue un Régimen con aspiraciones totalitarias (Cayuela, 2014) que dio continuidad reforzada a las políticas caciquiles y de control social que venían desarrollándose en España desde el último tercio del siglo XIX (Nicolás, 1982).

Durante la Guerra Civil y la dictadura fascista se consolidaron en Murcia las redes de poder local rural caciquil, que se venían tejiendo desde el último tercio del siglo XIX, con la imprescindible colaboración de las clases sociales mixtas agrarias (Capecchi y Pesce, 1984); es decir, pequeños propietarios agrícolas que combinaban trabajo por cuenta ajena y por cuenta propia. En efecto, el caciquismo no es un fenómeno impuesto de arriba abajo sin resistencias, es necesario conseguir la participación, o al menos evitar la reacción a la contra de las clases populares y subalternas para que la red de poder caciquil pueda existir y desarrollarse. Una cuestión más fácil de imponer si se controla un estado autoritario y represivo. En este sentido podemos entender el caciquismo como «no sólo un mecanismo de corrupción política y electoral impuesto desde arriba, sino también como una estructura de poder creada desde abajo para proteger los intereses de los grandes propietarios» (Gómez y González, 1999: 143).

Tras la guerra, otra forma de conseguir la aquiescencia política en los territorios del sur peninsular, además de la represión y la humillación, fue facilitar la paulatina incorporación política de nuevos agentes sociales que no habían tenido participación, destacada al menos, durante la contienda civil, pero que tras la misma se integraron o fueron invitados a integrarse como colaboradores/ayudantes de los cuadros fascistas que ejercían poder político local (Del Arco, 2011). En este sentido, la Falange Española de las JONS, violento partido nacionalsindicalista, jugó un rol central en la politización y control de las poblaciones rurales (Rodríguez y Lanero, 2014). Esta inserción flexible de nuevos cuadros políticos fue la base de la construcción social de lo que algunos historiadores han llamado el «puzle del consenso» (Del Arco, 
2011; Ortega y Cobo, 2011) que se desarrolló en función de las peculiaridades políticas, económicas y sociales de cada municipio.

En definitiva, el fascismo español no fue una dictadura rígida y monolítica controlada por los mismos caciques de siempre, sino que supo incorporar y politizar a amplias capas sociales a su causa para que actuasen como fuerza de choque y de control político en los pueblos. Éste es el germen del que florecieron dos formas de entender las relaciones sociales que confluyeron en las zonas rurales de Murcia propiciando el asentamiento definitivo de las redes de dominación caciquil local. De una parte, se fue constituyendo y consolidando la élite caciquil de poder, una suerte de «coalición reaccionaria protofascista», que disponía de todos los dispositivos de control político. Esta coalición fue la base sobre la que décadas más tarde se cimentaron las coaliciones de crecimiento económicas que controlarán el proceso de modernización y el modelo productivo de la Vega Alta. Por otro lado, se fue constituyendo y consolidando también el peso de la creciente ideologización y politización fascista de pequeños propietarios agrícolas y el sometimiento violento y la persecución del resto, sobre todo de jornaleros, desposeídos y afectos a la república. Se imponía una visión hegemónica del mundo rural basada en el catolicismo social conservador; la defensa de un universo simbólico y valores morales antidemocráticos (Del Arco, 2011) cuya sombra alargada llega hasta la actualidad. La dictadura supo y pudo establecer una «cadena de lealtades y fidelidades familiares y vecinales» (Del Arco, 2011; Mir, 2000) mediante el ejercicio de la represión, lo que fortaleció el asentamiento definitivo de las redes caciquiles. En este sentido, los consistorios fueron (y son) agentes de politización y control de primer orden, porque es la administración política más cercana a la población, absolutamente central en territorios rurales y disgregados. Son los lugares «donde la política se hace carne y se transforma en decisiones con trascendencia inmediata para el conjunto de la población» (Cabo y Veiga, 2011: 33). En definitiva, tanto ayer como hoy, el poder local no institucionalizado (las élites) tiene interés en controlar el poder local institucionalizado de los ayuntamientos. 
A mi juicio una de las grandes victorias simbólicas e históricas del discurso de las clases dirigentes es haber conseguido convencer a los pequeños propietarios, las clases medias y una porción variable de la clase trabajadora, de que comparten intereses con los grandes empresarios, que no están muy alejados en cuanto a estatus social. Esta peligrosa confusión de intereses de clase se produce al mismo tiempo que las clases medias no sólo no se identifican con las clases populares, sino que además intentan no ser como ellas. Se trata de un tipo de enclasamiento social más simbólico que real, pues gran parte de esas clases medias trabajadoras eran (y son) principalmente asalariadas; es decir, venden su fuerza de trabajo a cambio de un salario. Esta extraña alianza de intereses de clases perdura fuertemente en el imaginario colectivo de la gran parte de la población que se define como clase media. ${ }^{5}$ En la práctica, supone que buena parte de las clases trabajadoras y medias defienden los postulados e imaginarios de las élites locales.

En este apartado he tratado de apuntar algunos aspectos fundamentales para tratar de comprender el crecimiento, asentamiento y reproducción de las élites locales que detentan el poder local. Las élites propietarias supieron aprovechar en su beneficio el orden social impuesto por la dictadura para fortalecer sus posiciones sociales y ejercer el poder y la dominación sobre las clases trabajadoras. Durante las primeras siete décadas del pasado siglo fueron adaptándose a las circunstancias para mantenerse en el poder, lo que consolidó una élite local constituida por familias propietarias que consiguió perpetuarse como verdaderos señores ${ }^{6}$ dominadores. Si a los primeros miembros de estas élite podemos catalogarlos de «pioneros», sus descendientes heredaron sus posiciones sociales; patrimonios, conocimientos y recursos, partiendo de una posición de salida ventajosa a la hora de abrirse paso en el mercado agroindustrial.

5. En el estudio $\mathrm{n}^{\mathrm{0}} 3004 \mathrm{del}$ CIS, la encuesta «Prestigio ocupacional y estructura social» Octubre 2013-marzo 2014. Se preguntaba sobre dónde se situarían los encuestados como clase social en una escala del 1 (la más baja) al 10 (la más alta): el 39,4\% se valoraban con un 5 ; el $20 \%$ con un 6 y el $10 \%$ con un 7 . En torno al $70 \%$ consideraban que pertenecían a la clase media-alta.

6. Escribo en masculino porque las élites estuvieron constituidas por hombres. Sólo en la época moderna alguna mujer gran empresaria agroindustrial ha conseguido insertarse en las coaliciones de crecimiento locales. 


\section{Coaliciones de crecimiento y formas de dominación local}

El modelo socioeconómico y productivo de la Vega Alta es prototípico del sur de Europa. Está caracterizado por formas específicas de capitalismo flexible; eventualidad asalariada; segmentación étnica y de género; elevada movilidad intersectorial; disponibilidad de un nutrido ejército de reserva de fuerza de trabajo; alternativas laborales limitadas en el sector industrial y la imbricación entre pequeñas empresas/trabajo informal/estrategias de reproducción (Bagnasco, 1991; Hadjimichelis y Papamichos, 1990; Mingione, 1993; Pedreño, 1998).

En otras palabras, los agentes sociales con capacidad de intervención en la articulación del modelo productivo, principalmente las élites políticas y económicas locales y regionales, potenciaron como vía de crecimiento comarcal un modelo productivo cimentado en el sector agroindustrial, caracterizado por una intensiva demanda eventual de fuerza de trabajo. Para poder satisfacerla, es necesario que el empresariado disponga de mecanismos de control de la fuerza de trabajo (Pedreño, Gadea y De Castro, 2014). Precisamente, son los intereses compartidos de los miembros que componen la élite económica y política los que favorecen que se unan para trabajar en un doble objetivo común: condicionar el modelo productivo para que siga sirviendo a sus intereses empresariales y reproducirse como la clase dominante.

En este sentido, las formas específicas e identificables de poder local en la Vega Alta las encarnan los grandes empresarios agroindustriales que constituyen junto a políticos (locales y regionales) una particular coalición de crecimiento (Logan y Molotch, 1987). En efecto, «la expansión del sector agroalimentario de la Región de Murcia ha estado impulsada por una compleja y conflictiva coalición de fuerzas sociales, políticas e institucionales, regionales y extrarregionales, que ha ido cambiando a lo largo del tiempo» (De Castro et al., 2017)

Una de las estrategias históricamente más importantes de la coalición de crecimiento agroalimentaria ha sido la de tratar de impedir, en la medida de lo posible, la existencia de alternativas laborales más atractivas que pusieran en riesgo la disponibilidad de fuerza de trabajo en los picos de producción agroindustrial. 
Un caso prototípico de cómo las élites locales y regionales utilizan su poder para condicionar la organización socio-productiva del territorio es el del polígono industrial fantasma de Abarán. La construcción y desarrollo del polígono fue la principal propuesta del PSOE local en las elecciones de 2003, que terminaría ganando por primera vez desde la restauración democrática. ${ }^{7}$ Durante los cuatro años de legislatura se construyó la estructura del polígono pero no dio tiempo a desarrollarlo en toda su extensión, por lo que nunca se convirtió en un polo de trabajo industrial. Actualmente está abandonado y las naves industriales que se terminaron de construir están ocupadas por rebaños de cabras.

El objetivo principal de las coaliciones de crecimiento sigue siendo prolongar su control y dominio paternalista sobre el mercado de trabajo y el modelo productivo local. Para conseguirlo, desarrollan lo que en términos weberianos denominaríamos herrschaft, esto es, formas de dominación estructuradas que permiten esperar que las órdenes serán obedecidas. Las formas de dominación, que ejerce la élite local organizada como coalición de crecimiento, encuentran esa voluntad de obedecer en las masas trabajadoras que de un modo u otro, condicionadas o no, favorecen con su aquiescencia legitimadora o su pasividad que se articulen las formas de dominación local.

Al igual que las coaliciones locales de poder se articulan y readaptan a los cambios históricos externos e internos del modelo socio-productivo, también se van modificando las formas de legitimación de los modos de dominación. De este modo para cada una de las generaciones predomina un modo de legitimación que está relacionada con el tipo de dominación. Las formas de dominación que ejerce la élite local que conforma la coalición de crecimiento es el resultado de la interconexión de los tres tipos ideales de dominación que teorizó Weber: la dominación racional, la tradicional y la carismática (Weber, 2007). A mi juicio, las tres formas se dan en las diferentes fases históricas de desarrollo de las coaliciones pero con diferente peso en cada ciclo. En este sentido, podemos afirmar que en cada una de las fases tiende a predominar un

7. La segunda vez que el Partido Socialista ha alcanzado la alcaldía del Ayuntamiento de Abarán ha sido en las últimas elecciones municipales en mayo de 2019 conformando un tripartito de gobierno con Izquierda Unida y Unidad y Desarrollo, un partido independiente abaranero. 
tipo de legitimidad y dominación por encima de las otras. Sin olvidar que son modos de dominación complementarios con un mismo objetivo: mantener y fortalecer (en la medida de lo posible) las posiciones de poder dominantes de los agentes que componen la coalición de crecimiento, manteniendo en una posición social subsumida a la clase trabajadora, especialmente a las mujeres, cuyo trabajo productivo ha sido históricamente desvalorizado y el trabajo reproductivo silenciado o impuesto como una obligación derivada de su género.

En la primera fase (tres primeras décadas de siglo xx), la de los primeros pioneros, el tipo de legitimidad que destacaba era la carismática porque se les envestía con características cuasi místicas de líderes carismáticos heroicos. En la segunda fase (década de los 60), la consolidación de las redes de dominación local durante la dictadura, se apuntaló la dominación carismática con el asentamiento del mito de los «hombres abaraneros hechos así mismos». Al mismo tiempo ganó peso la forma de dominación tradicional porque el sistema político fascista promovía la obediencia local a las personas afectas al régimen que ocupaban puestos de poder, fueran cargos políticos o empresarios. En la tercera generación, ya en democracia, despunta la dominación legal-racional, donde la obediencia se presta a un ordenamiento legal. En los últimos años se ha producido en la Vega Alta una «profundización en la articulación de los procesos de control social de la mano de obra, a través del fortalecimiento de la intermediación, la difusión del ejército industrial de reserva y la inserción subalterna de los trabajadores migrantes» (Avallone y Ramírez, 2017: 158). En este caso, podríamos hablar de una cuarta generación, la de la era de la comercialización global, que no vamos a desarrollar en este artículo.

\section{Capacidad adaptativa de las élites}

Las élites locales comprendieron pronto que debían desplegar sus estrategias para conservar y fortalecer el poder acumulado durante y después de décadas de dictadura. La organización en coaliciones de crecimiento favorece que la élite actúe con autoconciencia de clase entendida como «los procesos 
subjetivos que conforman las decisiones intencionales» (Wright, 2015: 272) con respecto a sus intereses de clase y las luchas que emprenden para conseguirlos. Si las clases populares desarrollan estrategias de reproducción social para tratar de obtener recursos suficientes para la supervivencia, las élites locales organizadas en coaliciones de crecimiento también despliegan sus propias estrategias de reproducción con el objetivo de consolidar y potenciar su posición dominante.

Las coaliciones de crecimiento no son estancas o inmóviles a lo largo del tiempo, se articulan y rearticulan adaptándose a las condiciones objetivas existentes, pero también a los cambios históricos, legales, tecnológicos, sociales y productivos. En esta dinámica adaptativa un factor clave es la competencia por insertarse en los mercados internacionales (De Castro et al., 2017). Importan las posibilidades de expansión de los mercados. Si las empresas tienen capacidad suficiente pueden seguir siendo pioneras en las transformaciones productivas, en la búsqueda de nuevos mercados y la inversión en conocimiento y uso de saber experto de múltiples formas: inversión en tecnología; en investigación sobre variedades frutícolas e insumos; necesidades infraestructurales; modos de transportar las mercancías más rápido y más lejos... así como presionar o promover cambios para su beneficio en las legislaciones laborales y medioambientales.

Para ello despliegan estrategias de reproducción formal e informal. La estrategia formal principal es la organización en entidades que defiendan sus intereses como colectivo y que hagan de interlocutoras con el poder político regional, estatal y europeo. En este sentido, se han organizado en entidades asociativas como la Asociación de Productores-Exportadores de Frutas, Uva de Mesa y Otros Productos Agrarios (APOeXPA) y la Asociación de Productores-Exportadores de Frutas y Hortalizas de la Región de Murcia (PROEXPORT). Organizaciones que forman un poderoso grupo de presión dentro de la patronal; que se esfuerzan por dificultar la sindicación y que son una voz reconocida y temida por los partidos políticos por su capacidad de movilización electoral, mayoritariamente alineados con postulados conservadores.

En un aspecto más informal, empresarios y políticos crean redes de afinidad y amistad, se conocen y se relacionan, hablan de sus necesidades y problemas, proponen vías de desarrollo, negocian entre sí. En varias de 
las entrevistas que realicé a trabajadores y trabajadoras de Abarán referían conocer de primera mano que los grandes productores y exportadores locales se reunían, a comienzo de temporada alta, en el reservado de un restaurante para discutir y negociar los precios de los productos y el salario que pagarían por hora trabajada a sus plantillas. Las relaciones personales y la afinidad, las redes de favores, el intercambio de información y las negociaciones entre ellos son fundamentales.

\section{I Nacimiento del mito del «abaranero hecho a sí mismo»}

En este epígrafe pretendo dar cuenta del peso que ha tenido la construcción social del mito del «hombre abaranero hecho a sí mismo» en el apuntalamiento de las estrategias de control sociolaboral de las élites empresariales y políticas.

El mito es el resultado de la suma de relatos procedentes de diferentes fuentes formales e informales que exaltaban y agrandaban el éxito que tuvieron los primeros grandes emprendedores y agroexportadores originarios de Abarán. Hombres cuya figura mítica se alimentó dotándoles de cualidades extraordinarias. En realidad, sí que fueron pioneros (emprendedores en el lenguaje ultraliberal y economicista actual), pudieron emprender sus aventuras comerciales y saciar sus ansias de expansión al disponer de recursos y el arrojo suficientes para fundar grandes empresas agroexportadoras de éxito internacional.

A mi juicio, lo más fascinante del nacimiento, crecimiento y consolidación del mito, es que no se debe únicamente a la propaganda y enaltecimiento de los voceros del poder, sino que su función social le supera. Es decir, tiene poder para convencer a las masas, haciendo posible que cualquier persona creyera, ${ }^{8}$ independientemente de su origen social o sus capacidades objetivas, que se puede alcanzar el éxito siempre que se mantenga la actitud adecuada y sea capaz de hacer todo lo que se requiera para triunfar. Desde inicios del

8. Parte de mi tesis discute si aún hoy el mito sigue teniendo la misma vigencia, por eso está puesto en pasado. 
siglo xx, el crecimiento del mito y la expansión agroindustrial caminan de la mano, retroalimentándose mutuamente, pero obviando las posiciones sociales desiguales de las que parten los actores implicados, sean empresarios o jornaleros.

En efecto, la expansión del mito ha edulcorado la explotación en el trabajo agrícola y la pobreza del modelo productivo. De este modo, se han ocultado las prácticas clientelares y de control político-económico local que han limitado las alternativas productivas con el objetivo de controlar la oferta de mano de obra.

En este sentido, a las formas objetivas de control político y económico se suman formas de control ideológico y simbólico, modos más subjetivos y esquivos de analizar. En nuestro caso mediante el nacimiento y la consolidación del relato mítico de los grandes hombres abaraneros hechos a sí mismos. En esta construcción ha sido clave la participación de los cronistas oficiales, periodistas y literatos que han barnizado de heroicidad y santidad las trayectorias laborales de unos pocos, que casualmente siempre eran hombres nativos, conservadores y católicos.

El primer gran hombre abaranero sobre el que se comenzó a cimentar el mito de los «hombres hechos a sí mismos» fue Nicolás Gómez Tornero. Empezó trabajando como encargado en un almacén de frutas y en unos pocos años se construyó una gran carrera como empresario durante los años 20 , y murió en 1951. En 2001 la Asociación de cronistas de la Región de Murcia editó un libro dedicado sobre los grandes hombres de la Región. En el capítulo dedicado a este hombre puede leerse:

Nicolás era una persona especial [...] era un hombre con gran «visión empresarial»y, al mismo tiempo, con una gran «sensibilidad social», y ésta en dos aspectos: en el ámbito laboral, es decir, dentro de su empresa; y en el ámbito municipal, o sea, en el contexto de su pueblo. En relación con su aspecto empresarial, él empezó llevando fruta a Madrid en bestias de carga, continuó como encargado de la fábrica de conservas Champagne Fréres Limited, hasta que se estableció por su cuenta en el negocio de la fruta, tanto en conserva como en fresco, comenzando así a amasar su fortuna. Pero no se limitó a lo agrícola, sino que diversificó su campo de acción y así supo invertir en el ámbito inmobiliario tanto en Madrid como en Murcia, haciéndose con edificios o solares en lugares estratégicos. Vivía gran parte del año en el Hotel Palace de Madrid [...] 
en relación con su sensibilidad social, en el ámbito de su empresa, lo fundamental para él era que a sus obreros no les faltara el trabajo y por ello no paraba la faena, aunque él perdiera dinero. Por lo que respecta a su pueblo, intervino con su capital en empresas tan importantes para el bienestar de Abarán como la Central Eléctrica, la red de abastecimiento de aguas y construyó a sus expensas el Asilo y la ermita de los Santos Médicos. Pero todo ello desde el anonimato casi total, no haciendo nunca ostentación de su generosidad y procurando que su nombre nunca apareciera. Por todos sus méritos, el día de su muerte el pueblo se paralizó y, cuando fue llevado al cementerio, allí fue velado durante casi un mes día y noche y, según testigos que aún viven, apenas sufrió los efectos de la corrupción. Quede con estas líneas constancia de la trayectoria de un gran hombre, de los que hoy son tan necesarios como escasos. (Asoc. Cronistas oficiales 2001 a: $25-26$ )

En este relato advertimos cómo fue construyéndose el mito. Un relato mitológico que atribuye características místicas a un hombre incorruptible, al menos en lo puramente orgánico... Un lenguaje y una forma de escribir que corresponden más a una fábula que a una crónica realista, pero los cronistas no son elegidos por su análisis sociológico de la realidad, sino por su cercanía al poder y su capacidad de construir relatos laudatorios en torno suyo. A partir de entonces, y hasta ahora, todo hombre blanco, católico y conservador que se lanzase a conquistar el mercado de fruta extranjero y tuviera cierto éxito era considerado un emprendedor con características especiales, capacidad de trabajo incansable que suplía sus deficiencias (por ejemplo idiomáticas) con su empeño y empuje.

\subsection{La consolidación del mito abaranero}

Los años 60 fueron los del inicio de la reestructuración y modernización del modelo productivo agroindustrial murciano (Pedreño, 1999; Pedreño, Gadea y Latorre, 2013) y español (Clar, Serrano y Pinilla, 2015).

En las décadas de los años 60 y 70 se consolidó el mito con la aparición de nuevos exportadores. Por norma general eran hombres muy vinculados con la Iglesia y el poder fascista de la dictadura. La mayor parte eran miembros del Opus Dei, por lo que tendieron a dotar de moral y ética religiosa a la 
organización del trabajo: el sacrificio por la empresa; el sentimiento de hermandad igualitario (rebatido por las desigualdades sociales); la austeridad; la sumisión de la mujer (esposa) al hombre (empresario) y la recompensa final si se trabaja duramente.

En la consolidación del mito, contribuyeron dos aspectos sociales interesantes que engordaron el ego y el orgullo de un municipio rural donde la vida transcurría con dificultades. Se generalizó un lema y se consiguió una hazaña deportiva. Los grandes hombres exportadores habían conseguido dar a conocer la comarca a nivel internacional creando líneas de comercio internacionales, especialmente con París y Londres, las dos grandes urbes que eran el máximo exponente de la modernidad. El orgullo y cierta incredulidad acerca de la relación que unía un pequeño pueblo murciano con estas grandes ciudades hicieron que se generalizara en el municipio y toda la región el lema de Abarán-París-Londres. ${ }^{9}$

El segundo evento social que, a mi juicio, ayudó a asentar el mito fue que uno de estos grandes empresarios de la zona, Carmelo Morte Juliá, presidía a inicios de los años sesenta el modesto Abarán Club de Fútbol. En junio de 1963, tras unas cuantas eliminatorias muy igualadas, «el Abarán» consiguió la epopeya de ascender a Segunda División Nacional. Era la primera vez que en España un club tan modesto de un municipio de menos de diez mil habitantes consiguiera alcanzar esa categoría profesional. Con dinero proveniente del agronegocio, el equipo pudo mantener la categoría durante dos temporadas. En 1996 el ayuntamiento gobernado por el Partido Popular organizó un homenaje público a los jugadores y directiva que lo hicieron posible. A día de hoy las gentes del pueblo, sobre todo las clases populares, aún comentan con orgullo esa gesta deportiva. Hoy día el club lucha por sobrevivir.

Esta supuesta identidad homogeneizadora y orgullosa abaranera, el sentirse capaces de llegar a cualquier sitio, de competir con cualquiera y de con-

9. Abarán-París-Londres hace referencia a la actividad exportadora de frutas de la localidad que conectaba por medio de las mercancías el pequeño pueblo con dos de las principales urbes europeas. Estas relaciones comerciales hicieron que las autoridades locales pidieran una estación de telégrafos para conectar directamente con sus compradores en Londres y París. La conocida expresión hace referencia tanto a la relación comercial, como a la red de telégrafos y al aspecto simbólico de la «grandeza» del espíritu emprendedor de los «grandes hombres abaraneros», tanto en la década de los años 20 como en las décadas de los 60 y 70. 
seguir el éxito son algunos de los muchos sentimientos de reconocimiento y orgullo que cimentaron el mito de los abaraneros hechos a sí mismos.

\subsection{La adaptación a la democracia}

Para conservar el poder local en democracia era necesario ganar elecciones, creando un partido si era preciso. El primer alcalde de la democracia fue Antonio Morte Juliá, alcalde durante unos meses al final de la dictadura. Era uno de los principales exportadores de la época. En las elecciones de 1983 se presentó por UCD y ganó con mayoría absoluta. No le gustó la disciplina de partido y fundó el partido Independiente UDI con el que ganó con mayoría absoluta las elecciones de 1987. Repitió como alcalde en 1991 tras llegar a un pacto con el Partido Popular para desbancar al PSOE que fue el partido más votado en aquellas elecciones. En 1995 Antonio Morte se retiró de la política tras 16 años initerrumpidos como alcalde. Aún hoy sigue celebrando anualmente una gran comida en su finca privada, en la que están invitados los grandes agroexportadores, políticos regionales y otros invitados ilustres de renombre. Como buen alcalde paternalista y conservador «solía reunirse con frecuencia con toda la plantilla de funcionarios, porque consideró que "el ayuntamiento era una gran familia, donde debíamos ayudarnos los unos a los otros"》 (Soler y López, 2001: 234).

\section{Conclusiones}

Para la «coalición de crecimiento» lo moral, lo normal es la expansión del modelo productivo que les garantiza ganancia y mantener el poder de las relaciones sociolaborales. La consolidación del poder de las diferentes coaliciones que se han ido conformando ha sido consecuencia de la aplicación de formas de dominación política, económica y simbólica por parte de las élites económicas y políticas. Un pilar fundamental en su desarrollo y consolidación fue la construcción de un relato laudatorio y épico de las trayectorias de los primeros pioneros exportadores. 
En la Vega Alta se ha prolongado lo que Ortega y Cobo llaman el «viejo orden agrario, caciquil y oligárquico» o lo que Sevilla Guzmán llamó la «sociedad agraria integrada» (Sevilla, 1983). No se han modificado en lo sustancial las posiciones sociales que ocupan las clases dominadoras y las clases dominadas. La concentración del poder económico y político local genera dinámicas centralizadoras que favorecen el despliegue de estrategias productivas y económicas que retroalimentan sus prácticas paternalistas de dominación y dependencia.

Cuando hemos entrevistado a personas mayores de 60 años como ex esparteros o trabajadoras de los almacenes hortofrutícolas de la zona, en sus relatos han aparecido como centrales las relaciones de poder clientelares como nos relataba una trabajadora abaranera:

yo pienso que históricamente la idiosincrasia del pueblo de Abarán es muy tendente al caciquismo. Hay personas que dicen «te he dado trabajo, voto...» dice el gran cacique $\mathrm{x}$. Hay familias que han votado enteras porque lo ha dicho... y si yo te arreglo este cuarto de baño y te doy esto y lo otro, tú me tienes que votar y si yo le regalo a tu hijo una botella de vino especial son siete votos... así firmes. (Entrevista a Natalia $)^{10}$ Las redes de poder local clientelar de la Vega Alta no han sido democratizadas del todo ni sus formas de control están superadas, si acaso, están ocultas tras un velo de modernidad que cae en cuanto se profundiza en la realidad social. Dos entrevistados me explicaron la reproducción de las formas de dominación clientelar del siguiente modo: «aquí había un señor feudal que hizo algunas cosas buenas pero era un señor feudal, se murió y luego vinieron varios más y hoy aún los tenemos y por encima de todos el gran señor feudal» (Entrevista a Pepe Tomás). Joaquín lo resume con esta sentencia: «El que siempre mandó aquí era un hombre que era exportador, empresario y exportador» (Entrevista a Joaquín).

La dependencia de los trabajadores con los grandes empresarios para obtener trabajo; la falta de alternativas productivas; la particular organización del trabajo familiar y las redes informales de poder, están en la base de las relaciones de dominación y de la estructura económica productiva

10. Los nombres son ficticios. 
de estos municipios. Prácticas de patronazgo y clientelismo que se mantuvieron fuertes durante la dictadura y que cambiaron poco con el acceso al voto. Según nuestra investigación, los notables de hoy en la Vega Alta son los grandes agroexportadores, ellos (y alguna mujer) son los que fomentan la práctica del clientelismo y el patronazgo.

Hay otra importante consecuencia. Las coaliciones de crecimiento, al propiciar y fomentar las redes de poder clientelar, históricamente dominadas por hombres, han contribuido a invisibilizar y desvalorizar la función social que las mujeres desempeñan tanto en su trabajo productivo en los almacenes, como el reproductivo en los hogares.

\section{Bibliografía}

Arcas, J., García, M., Hernández, I., Martínez, I., Olmedo, A., Montes, J. y Sabater, R. (2014). Análisis del sistema de ciencia, tecnología e innovación agroalimentaria en la Región de Murcia. Cuadernos de Estudios Agroalimentarios, vol.6, 171-204.

Asociación de Cronistas Oficiales de la Región de Murcia (2001 a). Murcia palmo a palmo II. Murcia: Asociación de Cronistas Oficiales.

Avallone, G y Ramírez A. J. (2017). «Trabajo vivo, tecnología y agricultura en el Sur de Europa. Una comparación entre la Piana dele Sele en Salerno (Italia) y la Vega Alta del Segura en Murcia (España)». AGER, Revista de Estudios sobre Despoblación y Desarrollo Rural, n. ${ }^{\circ}$ 23. Zaragoza pp. 131-161.

Bagnasco, A. (1991). Desarrollo regional, sociedad local y economía difusa. En E. Reynaud; M. Maruani y C. Romani (1991), Debates sobre el empleo [1] en Italia. Madrid. Ministerio de Trabajo y Seguridad Social

Bourdieu, P. (2012). La distinción. Madrid: Taurus.

Cabo, M. y Veiga, X. R. (2011). La politización del campesinado en la época de la Restauración. Una perspectiva europea. En T. M ${ }^{\mathrm{a}}$. Ortega López y F. Cobo Romero (eds) La España rural, siglos XIX y XX: Aspectos políticos, sociales y culturales, pp. 21-59. Granada: Editorial Comares. 
Colectivo IOE y OrTí, A. (2007). La convivencia en Madrid. Discursos ante el modelo de desarrollo de la ciudad y la instalación de población inmigrante. Madrid: Observatorio de las Migraciones y de la Convivencia Intercultural de la ciudad de Madrid. Recuperado de: https:// www.colectivoioe.org/uploads/cd378eccdc4f7742c20992da3b66cfa4a452bf99.pdf

Capecchi, V. y Pesce, A. (1984). Si la diversidad es un valor. Valencia: Debats, nº 10 , pp. 29-49.

Castillo Alonso, J. J. (1979). Propietarios muy pobres. Sobre la subordinación política del pequeño campesinado. La Confederación Nacional Católica Agraria (1917-1942). Madrid: Servicio de publicaciones Agrarias. Ministerio de Agricultura. Recuperado de: https:// www.mapa.gob.es/ministerio/pags/biblioteca/fondo/pdf/24551_all. pdf

Cayuela, S. (2014). Por la grandeza de la patria. La biopolítica en la España de Franco. Madrid: Fondo de Cultura Económica de España.

De Castro, C. (2014). La desdemocratización de las relaciones laborales en los enclaves globales de producción agrícola. En A. Pedreño (coord.), De cadenas, migrantes y jornaleros: los territorios rurales en las cadenas globales agroalimentarias. Madrid: Talasa.

De Castro, C.; Gadea, E. y Pedreño, A. (2014). Inmigración, crisis del sur de Europa y sostenibilidad social de las estrategias de desarrollo. El caso de los enclaves productivos de agricultura intensiva. Revista Trabajo, tercera época, año 8, $\mathrm{n}^{\circ} 11, \mathrm{pp}$. 89- 115. Recuperado de: http://www2.izt.uam.mx/sotraem/Documentos/Revistadetrabajo11 final.pdf

De Castro, C; Gadea, E; Pedreño, A, y Ramírez, A. J. (2017). Coaliciones sociales y políticas en el desarrollo del sector agroexportador: las frutas murcianas en las redes globales de producción agroalimentaria. Revista Mundo Agrario. Argentina.

De la GaRza, E. (2018). La metodología configuracionista para la investigación. México: Editorial Gedisa. Universidad Autónoma Metropolitana. Unidad Iztapalapa. Recuperado de: http://www2.izt.uam.mx/ sotraem/NovedadesEditoriales/MetodologiaConfig_SD.pdf

Del Arco, M. A. (2011). Los franquistas del campo. Los apoyos sociales rurales del régimen de Franco. En T. M ${ }^{\mathrm{a}}$. Ortega López y F. Cobo Romero (eds.) La España rural ,siglos XIX y XX: Aspectos políticos, sociales y culturales. Granada: Junta de Andalucía. Editorial Comares. 
Gómez Oliver, M. y González, M. (1999). Por una nueva interpretación de la historia de Andalucía. Revista Ayer, no 36, pp. 131-144.

Hadjimichalis, C. y Papamichos (1990). Desarrollo local en el sur de Europa: hacia una nueva mitología. Andalucía: Revista de Estudios Regionales, $\mathrm{n}^{\mathrm{o}} 26$, pp. 113-144.

Levy, D. (2008). Political Contestation in Global Production Networks. Academy of Management Review, 33.

Logan, J. y Molotch, H. L. (1987). Urban Fortunes. The Political Economy of Place. Los Ángeles: University of California Press.

Mingione, E. (1993) Las sociedades fragmentadas: una sociología de la vida económica más allá del paradigma del mercado. Madrid: Ministerio de Trabajo y Seguridad Social.

Ortega, T. Ma y Cobo, F. (eds.) (2011). La España rural, siglos XIX y XX: Aspectos políticos, sociales y culturales. Junta de Andalucía. Granada: Editorial Comares.

Malefakis, E. (1977). Reforma agraria y revolución campesina en la España del siglo XX. Barcelona: Ariel.

Mir, C. (2000). Vivir es sobrevivir. Justicia, orden y marginación en la Cataluña rural de posguerra. Lérida: Editorial Milenio.

Nicolás, M. E. (1999). Los poderes locales y la consolidación de la dictadura franquista. Revista Ayer, n³3, pp. 65-86.

- (2003). Por una historia crítica de la memoria: valoración del franquismo y la transición desde la Región de Murcia. Pasajes: revista de pensamiento contemporáneo, $\mathrm{n}^{\circ} 11$, pp. 35-39.

Pedreño, A. (1998). Del jornalero agrícola al obrero de las factorías vegetales. Estrategias familiares y nomadismo laboral en la ruralidad murciana. (Tesis Doctoral). Departamento de Sociología e Historia Económica. Universidad de Murcia.

-(1999). Del jornalero agrícola al obrero de las factorías vegetales. Madrid: Ministerio de agricultura, pesca y alimentación.

-(coord.) (2014). De cadenas, migrantes y jornaleros: los territorios rurales en las cadenas globales agroalimentarias. Madrid: Talasa.

Pedreño, A.; Gadea, E. y de Castro, C. (2014) Labor, Gender and Political Conflicts in the Global Agri-food System. The case of Agri-export model of Murcia, Spain. En A. Bonanno. y J. S. Cavalcanti (eds.), Labor Relations in a Globalized Food (pp. 193-214). Bingley: Emerald. 
Pedreño, A.; Gadea, M. E. y Latorre M. (2013). Nuevos y viejos conflictos jornaleros en Murcia, 1890-2012. Comunicación al Congreso nacional de Sociología de la F.E.S. España. Recuperado de: https:// www.fes-sociologia.com/nuevos-y-viejos-conflictos-jornaleros-en-murcia-1890-2012/congress-papers/1708/

Ramírez, A. J. (2019). Hacia una nueva cuestión meridional. Crisis de reconocimiento y heridas morales en las clases populares de la Vega Alta del río Segura (Región de Murcia). Tesis Doctoral. Universidad de Murcia.

Rodríguez, O. y LANero, D. (2014). Juventud y campesinado en las falanges rurales: España, 1939-50. Historia Agraria, nº 62, pp. 177-216.

San Miguel del Hoyo, B. (1998). Los trabajadores de la industria del calzado de Elche: cambios en las condiciones de vida y de trabajo (19601997). Tesis doctoral. Universidad de Alicante.

Sanz Lafuente, G. (2011). Organización económica, movilización y catolicismo. En $\mathrm{M}^{\mathrm{a}}$ y Cobo Romero, F. (eds.), La España rural, siglos XIX y XX: Aspectos políticos, sociales y culturales, pp. 89-125. Granada: Junta de Andalucía. Editorial Comares.

Soler, P. y López Pascual, E. (2001). Líderes murcianos $S$. XX (IV Volúmenes). Siglo xx Líderes editorial, S. L. Murcia.

Weber, M. (2007). Sociología del poder. Los tipos de dominación. Madrid: Alianza editorial.

Wright, E. O. (2015). Clases. Madrid: Siglo XXI. 
